\title{
Preconditions for district nurses' telephone counselling during call-time in municipal home care: An observational study
}

\author{
Lise-Lotte Jonasson', Ann Holgersson', Maria Nytomt ${ }^{3}$ \\ and Karin Josefsson'
}

\begin{abstract}
Telephone counselling is a growing and complex task for district nurses in municipal home care, especially during evenings and at weekends. Work at call-time is often handled via telephone from cars, without access to records or other information about patients. There is a lack of research in this subject. The aim of this study was to explore preconditions for district nurses' telephone counselling at call-time. An observational study with an inductive approach was conducted. A structural protocol was used with a following open question. Seven district nurses who worked in home care in two municipalities in Sweden participated. Data were analysed using content analysis. Five categories were identified: 'availability', 'professionalism', 'communicability, 'secure approach', and 'technical approach'. Accessibility appears to be given priority over security. Ethical reflection is required on telephone management policy for district nurses' telephone counselling while driving and other interventions that require undivided attention.
\end{abstract}

\section{Keywords \\ call-time, district nurse, municipal home care, observational study, telephone counselling}

Accepted: 17 June 2016

\section{Introduction}

Every nurse who has spoken with a patient over the phone has practiced telehealth nursing. ${ }^{1}$ Telephone counselling is a growing and complex part of nurses' work in Australia, New Zealand, ${ }^{2}$ the USA, ${ }^{3}$ and several other Western countries. ${ }^{4}$ Yet, there is limited research regarding the nursing performed by district nurses (DNs) via telephone at calltime in municipal home care.

In most parts of Sweden, responsibility for home care is transferred from the 20 county councils to the 290 municipalities. $^{5,6}$ Both municipalities and county councils are autonomous organisations and have responsibility for various activities in health care. ${ }^{5}$ Home care is defined as care that takes place in a patient's home, typically ongoing, and where interventions have preceded the care with social care planning. ${ }^{7}$ Municipal home care is delivered through interdisciplinary teamwork, even though DNs often work independently. With their unique role combination of responsibility for nursing and medicine, DNs play a key role in the home care team. ${ }^{6}$

In municipal home care, DNs work at call-time, in other words weekends, evenings, and nights. An increasing number of people receiving home care have different care needs. ${ }^{6,7}$ District nurses use telephones as a work tool as well as a precondition for managing work tasks and for being available. ${ }^{6}$ At the same time, DNs have limited access to information about the patients since they are mobile during their shifts. Therefore, DNs must rely on the competence of other staff and delegate tasks; something which could pose risks to patient safety. ${ }^{6,7}$

Nursing via telephone includes advice giving, coordination, communication, information, support, training, and triage referrals. ${ }^{1,4,8}$ These demands require competences in telehealth nursing. The ability to communicate clearly over the phone is important, as calls are usually short and nonverbal cues cannot be relied upon. Non-verbal communication (i.e. communication through sending and receiving wordless cues), facilitates DNs' establishment of good interaction fostering trust. Active listening is a precondition, and a DN's voice needs to convey interest and confidence. ${ }^{1,4,8}$ In order to meet these demands, DNs need to be pleasant, sympathetic, and give good advice and guidance. ${ }^{8}$ Also, it

'Faculty of Caring Science, Work Life and Social Welfare, University of Borås, Sweden

${ }^{2}$ Health Centre, Alingsås, Sweden

${ }^{3}$ Vara Health Centre, Sweden

\section{Corresponding author:}

Lise-Lotte Jonasson, Faculty of Caring Science, Work Life and Social Welfare, University of Borås, 50I 90 Borås, Sweden.

Email: lise-lotte.jonasson@hb.se 
is important to cooperate and show respect without a patronising attitude. ${ }^{1,4,8}$

The Health and Medical Service Act in Sweden states that all citizens are entitled to good and safe care when needed. ${ }^{9}$ As expressed in the International Council Code of Ethics for Nurses (ICN), all patients, relatives, and professionals should feel safe and be met with respect and with regard to everyone's equal value. ${ }^{10}$ The ICN involves four fundamental responsibilities: to promote health, to prevent illness, to restore health, and to relieve suffering. Essential in nursing is to respect human rights. This includes the right to life, to dignity, and to be treated with respect. The ICN also expresses seven ethical values: respect, equity, professionalism, participation, beneficence, quality assurance, and safety. ${ }^{11}$ Telehealth nursing ought to be performed according to ethical codes and values. This means that DNs must consider ethical codes and values during telephone counselling.

\section{Aim}

The aim of this study was to explore the preconditions for district nurses' telephone counselling at call-time.

\section{Research design and ethics}

The research design was explorative with an inductive approach. ${ }^{12}$ The study was performed in 2015, in the home care services in two municipalities in Western Sweden. Seven DNs participated in the study. A structural observational protocol was created with a following open question. ${ }^{12}$ Data were analysed using content analysis. ${ }^{13}$

Informed agreements were received from managers at the municipal home care units. Before participants gave informed consent, they were provided with information about the study. Participants were informed that participation was voluntary and that they could withdraw at any time. They were guaranteed confidentiality and anonymous presentation of the findings. Further ethical aspects were considered based on the World Medical Association Declaration of Helsinki. ${ }^{14}$

\section{Sample and data collection}

Convenience sampling was used. Seven DNs participated who had given their informed consent to participate in the study: six women and one man. The group included all those who were available and all agreed to participate in the study. They had worked from three to twelve years in municipal home care. All participants had Swedish as their native language.

Data were collected by two of the authors $(\mathrm{AH}$ and $\mathrm{MN}$ ) via an observational study since this approach allows the researcher to study events and behaviours as they occur. Also, it allowed telephone communication to be seen in its natural context. ${ }^{12,15} \mathrm{~A}$ structural protocol was created for this study, with its focus on DNs' attitudes towards telephone calls; tone of voice, such as happy, angry, supportive, rejection, encouraging, or annoying; and non-verbal communication, such as expressions, gestures, sighs, or eye movements.

The observations were carried out as follows: At the beginning of an observation session, the observers presented themselves and the study (again) for the participants. The observers made clear that they would not review the DNs' work but merely focus on their telephone calls. The observers' approach was to stay in the background, as invisible as possible during the actual observation, and to provide analytical thoughts and reflections after the observation was completed and with some distance from it. ${ }^{15}$

District nurses were observed during 30 telephone calls at call-time when talking to patients' next of kin, nurse colleagues, health care staff, and home service staff. The telephone calls took place either at the DN's clinical reception, during home visits, or in the car. Each observation lasted two to six hours, with a total time for all observations of about 23 hours. All observed phone calls were documented. The character of the phone calls varied depending on the person who called. The focus of the study was on the DNs who performed the phone calls, not the number of people.

The observations were continuously documented, written down, and compiled. ${ }^{16}$ After each observation, time was set aside for the observer to reflect and write down a short piece of text. This was done with the purpose of reflecting both on how the interpretation came to light and on how the researcher would interpret their own interpretation of the phenomenon. This interpretation is important in order to reach a credible result. ${ }^{12}$ The observer's reflection can also give an increased understanding of the data analysis process. $^{12}$

In order to get a more reasonable picture and understanding of the observed phenomenon, the participants received a written open question after completing the observations: ${ }^{12}$ 'How do you experience working on call and using a telephone as a tool?' Six out of seven participants answered the question via email or SMS.

\section{Data analysis}

A qualitative content analysis was carried out. ${ }^{13}$ The analysis began with reading field notes, observation notes, and answers to the follow-up question several times in their entirety to get an overview of the content. Meaning units were identified and condensed, describing preconditions for DNs' telephone counselling with focus on DNs' attitudes towards telephone calls, tone of voice, and nonverbal communication. Thereafter, these condensed meaning units were abstracted into codes. Then, the content of the different codes was compared in order to discern similarities and differences. Codes with similar content were grouped together into 10 sub-categories. In the final stage of the analysis, the content of the sub-categories was compared and abstracted into five categories. The analysis was thoroughly discussed in the research group until consensus was reached. The different steps in the analysis were also discussed in the research group and in several seminars. Table 1 shows an example of the content analysis process. 
Table I. Example of the content analysis process.

\begin{tabular}{|c|c|c|c|c|}
\hline Meaning unit & Condensed meaning unit & Code & Sub-category & Category \\
\hline $\begin{array}{l}\text { DN seems irritated being } \\
\text { bothered about } \\
\text { answering correctly } \\
\text { and nicely over the } \\
\text { telephone inside the } \\
\text { patient's bedroom }\end{array}$ & $\begin{array}{l}\text { DN seems annoyed by dis- } \\
\text { turbances from the patient } \\
\text { but responds in a correct } \\
\text { and nice way anyway }\end{array}$ & $\begin{array}{l}\text { The telephone rings when } \\
\mathrm{DN} \text { is in the patient's } \\
\text { bedroom and home }\end{array}$ & Professional ethics & Professionalism \\
\hline
\end{tabular}

Table 2. Overview of sub-categories and categories.

\begin{tabular}{ll}
\hline Sub-category & Category \\
\hline $\begin{array}{l}\text { Always reachable and constantly } \\
\text { interrupted } \\
\text { Constantly available } \\
\text { Competence and responsibility }\end{array}$ & Availability \\
$\begin{array}{l}\text { Professional ethics } \\
\text { Listen, explain, teach, and advise }\end{array}$ & Professionalism \\
$\begin{array}{l}\text { Willingness to cooperate } \\
\text { Delegation }\end{array}$ & Communicability \\
Security & Secure approach \\
Traffic safety & \\
Attitude to technology & \\
\hline
\end{tabular}

\section{Findings}

The findings explore preconditions for district nurses' telephone counselling during call-time in municipal home care. The findings are organised into the five categories that emerged from the content analyses: availability, professionalism, communicability, secure approach, and technical approach (Table 2). Within these categories are 10 sub-categories (Table 2). The sub-categories are reported on individually in the sections below.

\section{Availability}

Availability was a precondition for DNs' telephone counselling during call-time. There were both internal and external demands on being available. The DNs wished to be available by phone, as well as being expected to be so by colleagues, home service staff and other health care facilities.

Always reachable and constantly interrupted. Observations showed that the DNs' way of working aimed at making them constantly reachable, which in turn resulted in situations where the DNs were willing to be interrupted in their work. Their telephones were not on silent at any time, expect for a few occasions, such as when they were talking with and taking care of patients in palliative care. Patients seemed to be accustomed to the fact that the telephone would distract the DNs sooner or later.

... mostly it works fine but it happens naturally that you feel frustrated if, for example, you are on home visits and it rings a lot. (DN3)
District nurses' work environment during call-time varies with the constant movements between patients and missions: home visits, visits to municipal accommodations, car rides, shorter walks between patients, and times at their own or a colleague's workplace and/or office. The observations showed that this way of working was normal and expected. The DNs were used to adapting to the situation and finding solutions 'here and now'. The observed DNs answered the telephone no matter where they were. To a large extent, the telephone steered their shifts and they were always willing to answer calls and prioritise accordingly. Based on the situation, they would find practical, immediate solutions to write down information, gather facts, etc. For example, they wrote down information on the nearest napkin or paper. Computer access was limited and only available inside certain municipal locations.

Based on the work environment's security aspects, the observation showed that DNs place high demands on themselves, for example to remember things without writing them down when they were unable to do so, to interrupt work tasks such as preparing pill organisers, to work without access to computers, and to constantly be prepared to reprioritise their work.

... the only negative thing is that I am always reachable and therefore can call at a maximum of unsuitable jobs. (DN4)

Several different ways of working were observed and all DNs created their own strategies. However, all observations were permeated by their priorities and everyone was eager to respond quickly when the telephone rang. Several times, though, the DNs' priority to respond came before safety. Without taking a whole situation into consideration, several DNs quickly answered the telephone. This could be while driving, for example in the middle of a turn, or when sorting drugs into pill organisers.

There were several observations where safety had to step back for availability. This approach was interpreted as if they were unconscious of when the will to be available took over. Direct and fast responses were expected, and here the DNs' personal demands on themselves shone through. Being constantly interrupted in one's work is not a good for anyone. Yet, the DNs' work at call-time was interrupted many times during the sessions. This distracts the DNs' attention and may cause risks.

... some evenings there are a lot of calls and you get interrupted all the time at work and have to refocus. (DN5) 
Constantly available. The observations clearly showed that all DNs gave high priority to meetings over the phone. The DNs obviously prioritised availability before safety, for example in terms of answering quickly, so irritability could emerge if phone calls were hindered by technology or other circumstances.

$$
\begin{aligned}
& \text {... the telephone is mostly for being available. The constant } \\
& \text { availability sometimes causes stress. (DN6) }
\end{aligned}
$$

\section{Professionalism}

The observations show that the DNs work with a professional approach, in terms of response, managing the care situation, and telephone meetings. None of the DNs demonstrated a flippant attitude or unwillingness, but showed interest in the call and the caller's willingness to be involved in health care.

Competence and responsibility. There were expectations on the DNs to answer questions, and to guide and solve different problems. Through the observation of a great deal of responsibility and the DNs' ability to prioritise on the basis of facts gathered from information about the patient from other staff and/or the patients themselves, the findings reveal that the DNs are highly skilled.

The responsibility of DNs was apparent both in patient situations and in interaction with other staff. They did not leave unresolved issues behind; instead their immediate answer would be to give planned feedback of the event in order to ensure safe handling. The observations also revealed the DNs' courage to delve into different situations via the telephone, for example when a $\mathrm{DN}$ calls the ward that dismissed the patient in order to receive more information about their care, or when a DN oversees that a patient receives prescriptions and their response to treatment. The DNs were observed to have a preparedness to manage these meetings according to needs required.

... to make judgements over the phone and even in isolated cases I give instructions according to The Health Care Act, even when I can't be there in person. (DN2)

Professional ethics. The observed DNs worked with a patient-centred approach. Their workplace is the patient's home. The DN is the guest of the person who receives care, which places special demands on sensitivity and humility. In that situation, having to shift your attention from the patient to an incoming phone call was something the DNs found frustrating. Often, the ringing telephone interrupted a call already in progress and distracted attention from the calling party. The observations noted that after the DN had finished the second telephone call, s/he went back to the original, ongoing conversation that had been interrupted. Both patients and DNs seemed to be accustomed to dealing with phone calls that way.
... our patients are almost always sympathetic and understanding when the telephone rings and you say to them that you have to answer it... but it doesn't feel ok to answer. (DN3)

The DNs tried to walk away when they answered the telephone, shield themselves, and spoke quietly. When the telephone rang during home visits, the DNs told the callers they would get back as soon as possible. The DNs often suggested a time span when they expected to be able to call back. There were often several people present when receiving these phone calls in a patient's home. The DNs said that it was not possible to organise their work differently than having the phone on for incoming calls and talking to callers when in patients' homes. During call-time, it was not possible to assign only a certain DN to manage the telephone calls since few DNs were on duty.

... I try to say as soon as I can to the caller that I'm on house calls...'can I call you back in about 20 minutes?' ... it is almost always ok for the staff. (DN3)

The DNs pointed out the value and importance of having good relationships with the staff who work with the patients. Several observations revealed the complex situation that emerges when DNs make decisions on the basis of an enrolled nurse's assessment of a patient. In this process, it was important that everyone involved understood their function and that every role is important. Throughout all observations, the DNs' supportive and affirmative attitude towards the caller was apparent. The DNs responded to all calls with respect and sensitivity, no matter what the call was about.

... it helps if the caller and the respondent are prepared and understand each other and 'speak the same language'. (DN1)

The DNs had an important role of displaying a calm and confident attitude towards the caller. On several occasions during the observations, the DNs' respect towards the caller was shown, for example through a supportive attitude. The DNs made sure that the caller would feel listened to and that they worked together with the patient but they were also careful to reinforce each other's roles.

... having the telephone as a working tool is a must for us when we work as we do. The staff need to be sure that they will be able to reach us. (DN3)

\section{Communicability}

The findings show that the mobile phone was one of the DNs' primary tools for working on-call in municipal home care. The callers were mostly home care staff and other colleagues. The number of calls during a shift varied greatly.

Listen, explain, teach, and advise. The DNs responded to calls quickly and politely, giving their names and titles. It was 
clearly observed that the DNs focused on what was being said, tried to pinpoint the problem, asked appropriate questions, and clarified questions or issues before they decided on how they would act on the information received from the caller. Occasionally, the DNs needed to reprioritise planned activities and then gave advice to other staff on how to proceed. The DNs responded to the staff's questions with calm and confidence. The content of the telephone calls often consisted of the DNs' given advice.

Most of the phone calls concerned direct care problems and opinions based on a patient's situation. An example from the observations was care staff phoning a $\mathrm{DN}$ when a patient demanded a urinary catheter, even though there was no medical indication according to the urologist and emergency physicians. The care staff felt pressured by the patient. The DN handled the situation by listening to the care staff when they talked about the dilemma. The DN asked questions that care staff then posed to the patient. The DN explained and gave advice on the basis of the prescription and situation. The DN also informed why a urinary catheter would not be used and planned a home visit to the patient and a follow-up conversation with the nursing staff later in the evening.

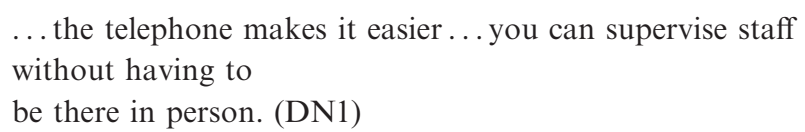

Willingness to cooperate. The DNs stressed that cooperation with other staff was important. The observations showed that many calls were rounded off with a more personal tone. The DNs would talk, laugh, and banter with the home care staff in a relationship-building manner.

The telephone used during call-time is neither personal nor adapted to an individual DN. Instead, the phone belongs to the work place. The address book contains a pre-set list of important telephone numbers of colleagues, different staff groups, and health care facilities. The observations revealed that DNs' communication was different when they saw in the display that a colleague was calling. The call tone became more personal and friendly.

\section{Secure approach}

Delegation. In order for municipal home care to function, a DN needs to delegate tasks to enrolled nurses. During the observations of the telephone calls, it was evident that home care was based on delegation. For example, when the DNs were geographically distant from a patient they would delegate giving medication and insulin injections. The DNs ensured that the enrolled nurses had responsibility for the task and that no one undertook a task they could not handle. Cooperation and trust in each other's knowledge was the basis for safe patient care. Cooperation between the DNs that worked during on-call shift was also much dependent on the telephone, especially since they did not meet for long periods of time during a work shift.
... with the telephone, I can delegate work tasks to colleagues either geographically closer to the patient, or with greater knowledge. (DN2)

Security. During call-time, an individual DN could be responsible for more than 100 patients. This means that they only had complete knowledge of a handful of these patients. Observations showed that the DNs were used to this situation and that they were careful to collect knowledge about the patient both via the caller and the patient record, if possible. Although, sometimes decisions were based on an image reproduced by a colleague or enrolled nurse. Observations showed that patient safety may be at risk when DNs get phone calls and are busy with a task. Sometimes it turned out that DNs used a paper napkin for written documentation. Municipal home care in Sweden is organised this way, though, and everyone seemed to be familiar with it and their respective roles. However, patient safety and accuracy pervaded their work and nothing seemed to be done at random. Documentation and signature lists were accessible in the patient's home. This made it easy to know what had been administered or done, for example when it came medication.

$$
\begin{aligned}
& \text {... using the telephone, I can ask about a patient's health } \\
& \text { and general condition } \\
& \text { by gathering information from the enrolled nurse or home } \\
& \text { care services. (DN2) }
\end{aligned}
$$

Traffic safety. Cars are a common and necessary means of transportation in municipal home care, as DNs travel great distances during shifts. Observations revealed that DNs often answered the phone while driving, which exacerbated the already stressful situation they were in. It was not always easy or even possible to stop the car during a conversation, which caused traffic safety issues for the DNs. Sometimes they had access to hands free, which made things easier. But there were problems getting a pen and paper to take notes about the health care situation being discussed. Based on several observations, the DNs obviously possessed a trained multitasking capacity. They took phone calls regardless of whether they were driving or not.

\section{Technical approach}

Attitude to technology. The observed DNs always worked with a telephone by their sides. In the form home care is now organised, this is one of the preconditions for its function. The DNs' attitude to technology affected how this was carried out. Those with a positive attitude towards a new mobile phone were not stressed by unfamiliar technology but rather saw it as a positive challenge. For them, the phone was considered essential. Several DNs also said they used GPS for navigation as well as the Internet to access FASS (Pharmaceutical Specialities in Sweden). However, not all DNs were equally positive about technology. For some, mobile phones could be a stress factor. 
... a telephone that is used in our profession should be adapted in both design and content, just like our documentation programme for nursing... I wish that someone could specialise in precisely what we need, not a lot of difficult apps that just bother me. (DN2)

\section{Discussion}

\section{Findings}

The findings showed preconditions for DNs' telephone counselling during call-time through five categories that emerged from the content analyses: availability, professionalism, communicability, secure approach, and technical approach. Within these categories are 10 sub-categories (see Table 2).

The observations showed that availability was a precondition for DNs' telephone counselling, as well as always being reachable and constantly interrupted. However, these findings revealed conflicting demands and a stressful work situation. ${ }^{17}$ The aim of DNs' work was patient safety, in line with the ICN's ethical value of professionalism. ${ }^{10,11}$ However, the demands on availability overshadowed several other things. The observations revealed an unreflective and perceived demand to answer incoming calls quickly, whether or not the DNs had access to hands free when driving. Also, they answered the phone while driving without access to a patient's records. By always responding quickly, the DNs acted seemingly unreflectively about the risks created. This could jeopardise both traffic and patient safety, which clashes with the ICN ethical values. ${ }^{10,11}$ At the same time, the reason for being available could be that they feel that their primary professional responsibility should be towards the people in need of care. ${ }^{10,11}$

We believe that society has become telephone-centred with high availability in human lives. This development could be reflected in the DNs' work. Working on-call hours means working with limited resources, such as few DNs on duty. This led us onto organisational factors as preconditions for DNs' telephone counselling. Working with limited resources, conflicting demands on availability and achieving nursing via telephone counselling might cause stress and feelings of insufficiency. ${ }^{17}$ There is a need to clarify these demands as they can cause counterproductive psychological and physical health outcomes. ${ }^{17}$

The DNs' competence and responsibility were preconditions for their telephone counselling, since there were expectations that they should be able to answer questions, guide and solve problems. A phone call is often short, which is why it is important to establish a good and trustful relation between the two speakers. ${ }^{8}$ Active listening is therefore a precondition, and so is the DNs being nice and sympathetic. It is important to maintain good interaction so that the caller feels trust and being listened to. ${ }^{8}$ By displaying a dismissive or patronising attitude, the DNs can give the impression of feeling or being superior. Therefore, mutual cooperation and respect is important. Before a call is finished, DNs should tie up loose ends, repeat what has been said, and offer the caller to call back if problems persist. $^{1,4,8}$ Showing respect, equity, and professionalism are in line with the ICN. ${ }^{10,11}$

Other preconditions for telephone counselling were the DNs' communicability and willingness to cooperate. Communicability was influenced by the DNs' desire to create participation, one of the ethical values of the ICN,${ }^{10,11}$ through their ability to listen, explain, teach, and give advice. The importance of communication in health care is mentioned more and more often, ${ }^{18}$ and for it to be effective, it is important that patients and staff understand each other. Each telephone conversation is unique, which is why we believe it important to raise the DNs' role in the telephone conversation, such as always presenting themselves and how they manage the calls. The DNs' knowledge about communication and transfer of information are of importance in telephone counselling, not least since DNs need to supervise and teach staff with regard to patient safety, for example in delegation to staff. ${ }^{19}$ This reflects fundamental responsibilities stated in the ICN, such as the importance of promoting health and relieving suffering over the phone. ${ }^{10,11}$

The observations revealed professional ethics as a precondition to DNs' telephone counselling. When the DN worked in the homes of patients in need of care, they also called patients, relatives and staff on the basis that they had different needs and needed the DN's help. This can be seen as conflicting demands, which requires ethical professionalism. According to the $\mathrm{ICN}^{10}{ }^{10}$ it is essential in nursing to show respect, equity, and professionalism. These ethical values ought to be apparent in all DNs' nursing via telephone in municipal home care. At the same time, it is an ethical balancing act to manage the telephone when DNs are in patients' homes. This was similarly pointed out in earlier research 10 years ago. ${ }^{20}$ In spite of that, ethical problems remain in telephone counselling, such as talking about staff and sensitive matters with third parties, i.e. not the care seekers. This confirms the need for guidelines for DNs' telephone counselling.

Findings revealed that technology could be both a facilitating work tool and a frustrating hindrance for the DNs' telephone counselling, depending on the situation. The DNs in this study always worked with a telephone by their sides as a precondition to achieving home care. However, not all DNs were equally positive about new technology. For those who were not, mobile phones could be a stress factor and experienced as creating unnecessarily high demands. One way to facilitate DNs' telephone counselling may be to use e-messages in communication with care staff. E-messages can complement communication and facilitate cooperation. ${ }^{21}$ That being said, we think that the technical solutions both for mobile telephones and care could be improved. Technology can be a security device in a DN's solitary work and when they travel distances during on-call time. ${ }^{22}$ But it can also pose threats and obstacles unless safety is taken into consideration when deciding what it should be used for and how. This observation study showed an urgent need for a policy 
regarding DNs' telephone counselling combined with car driving.

\section{Methods}

To achieve trustworthiness of the findings, we discuss credibility, dependability, transferability, and preunderstanding. ${ }^{12,13}$ The choice of observations as a method was based on the assumption that observers can see relationships between different events. After literature studies, an observation protocol and an open interview question were created. This was discussed with colleagues at several seminars. We believe that it will strengthen the study's credibility and dependability. The analysis process was discussed until the researchers reached an agreement, and was also discussed with colleagues at several seminars. The intention was to clearly describe the method and results with descriptive quotations.

The transferability of the findings is limited since the sample not was chosen at random. However, DNs working with telephone counselling in municipal home care might recognise themselves in the findings.

The authors have long experience of working as registered nurses but have limited experience in telephone counselling in municipal home care. This can be strength when the observers have been able to have an openness and curiosity regarding their observations of the DNs' telephone counselling. Triangulation of data is important to improve the probability that the findings will be found credible. ${ }^{12}$ Trustworthiness can be strengthened by using several data sources, such as field notes, observations, and answers to the follow-up question. At the same time, the researchers' preunderstanding may influence observations. Therefore, the researchers reflected and wrote down their preunderstanding. An increased awareness of a person's preunderstanding can increase the likeliness for a more neutral observation and analysis process, which reduces the risk that the results are affected.

No ethical problems or conflicts occurred during the study.

\section{Conclusions and clinical implications}

There is a need for an ethical discussion about handling telephones in DNs' work, in patients' homes and in the car. This discussion should result in guidelines concerning DNs' telephone counselling. Technology should also be adapted to DNs' individual needs in municipal home care. Therefore, it is desirable that the municipalities urgently seek a more secure technical solution for DNs' cars. For example, the municipalities could equip DNs with individual mobile phones adjusted to their personal needs in terms of apps, settings etc. Then, incoming calls could be forwarded to the individually adapted mobile phones. Our study suggests further research in order to explore DNs' constantly changing work environment in municipal home care.

\section{Acknowledgements}

We are grateful to all participants in this study.

\section{Funding}

This research received no specific grant from any funding agency in the public, commercial, or not-for-profit sectors.

\section{Conflict of interest}

The authors declare that there is no conflict of interest.

\section{References}

1. American Telemedicine Association. Telehealth nursing fact sheet. Washington, DC: American Telemedicine Association, 2011.

2. St George I, Cullen M, Gardiner L, et al. Universal telenursing triage in Australia and New Zealand - a new primary health service. Aust Fam Physician 2008; 37: 476-479.

3. Schlachta-Fairchild L, Varghese SB, Deickman A, et al. Telehealth and telenursing are live: APN policy and practice implications. J Nurse Pract 2010; 6: 98-106.

4. Wahlberg AC. Telephone advice nursing: callers' perceptions, nurses' experience of problems and basis for assessments. $\mathrm{PhD}$ Thesis, Karolinska Institutet, Sweden, 2004.

5. The Swedish Institute. Health care in Sweden, https://www. santesuisse.ch/user_content/files/infosantesuisse_dossiers/29 sweden_healthcare_e_20110325085133.pdf (2009, accessed 1 June 2016).

6. Josefsson K and Peltonen S. District nurses' experience of working in home care in Sweden. Healthy Aging Res 2015; 4: 37. DOI: 10.12715/har.2015.4.37.

7. Josefsson K. Tio punkter för en god och säker hemsjukvård för äldre personer [Ten points for a good and secure home care for older adults]. Stockholm: Swedish Society of Nursing and the Swedish Association of Health Professionals, 2010.

8. Ledin A, Olsen L and Josefsson K. Sjuksköterskors syn på svårigheter i telefonrådgivning: En litteraturstudie. Nord $J$ Nurs Res 2011; 31: 11-18.

9. SFS. Hälso- och sjukvairdslag [The Health and Medical Service Act]. Stockholm: Ministry of Health and Social Affairs, 1982.

10. International Council Code of Ethics for Nurses, http://www. icn.ch/images/stories/documents/about/icncode english.pdf (2012, accessed 4 April 2016).

11. Jonasson L, Liss P, Westerlind B, et al. Empirical and normative ethics: a synthesis relating to the care of older patients. Nurs Ethics 2011; 6: 814-824. DOI: 10.1177/ 0969733011405875.

12. Polit DF and Beck CT. Essentials of nursing research: appraising evidence for nursing practice. 8th ed. Philadelphia, PA: Lippincott, 2013.

13. Graneheim UH and Lundman B. Qualitative content analysis in nursing research: concepts, procedures and measures to achieve trustworthiness. Nurse Educ Today 2004; 24: 105-112.

14. World Medical Association. World Medical Association declaration of Helsinki: ethical principles for medical research involving human subjects, http://www.wma.net/en/ 30publications/10policies/b3/17c.pdf (2013, accessed 1 June 2016).

15. Dahlberg K, Dahlberg H and Nyström M. Reflective lifeworld research. Lund: Studentlitteratur, 2008.

16. Emerson R, Fretz R and Shaw L. Writing ethnographic field notes. Chicago, IL: University of Chicago Press, 1995. 
17. Josefsson K, Sonde L, Winblad B, et al. Work situation of registered nurses in municipal elderly care in Sweden: a questionnaire survey. Int J Nurs Stud 2007; 44: 71-82.

18. Fossum B. Modeller och teori för kommunikation och bemötande [Models and theory of communication and response]. Lund: Studentlitteratur, 2007.

19. Karlsson B, Morberg S and Lagerström M. Starka som individer men svaga som grupp: en kvalitativ studie om hur distriktssköterskor upplever sin arbetssituation och hur de ser på sitt yrke [Strong as individuals but weak as a group: a qualitative study about district nurses' perceptions of their work situation and their occupation]. Nord J Nurs Res 2006; 26: $36-41$.
20. Holmström I and Höglund A. The faceless encounter: ethical dilemmas in telephone nursing. $J$ of Clin Nurs 2007; 16: $1865-1871$.

21. Lyngstad M, Grimsmo A, Hofoss D, et al. Home care nurses' experiences with using electronic messaging in their communication with general practitioners. J Clin Nurs 2014; 23: 3424-3433.

22. Tourangeau A, Patterson E, Rowe A, et al. Factors influencing home care nurse intention to remain employed. $J$ Nurs Manag 2014; 22: 1015-1026. 